\title{
Genotype-environment interaction in layer chickens in the growing stage: comparison of three genotypes at two different feeding levels with or without red mite (Dermanyssus gallinae) infestation
}

\author{
Hakan Erdem and Türker Savaş \\ Department of Animal Science, Faculty of Agriculture, Çanakkale Onsekiz Mart University, \\ 17020 Çanakkale, Turkey \\ Correspondence: Türker Savaş (turkersavas65@gmail.com)
}

\begin{abstract}
Received: 29 April 2021 - Revised: 1 September 2021 - Accepted: 23 September 2021 - Published: 15 October 2021
\end{abstract}
\begin{abstract}
This study investigated how early growth was affected in various chicken genotypes, which were fed ad libitum or restricted and with or without poultry red mite (PRM) infestation. Atak-S (AS), New Hampshire Red (NHR), and Light Sussex (LS) genotypes were used in the study. In total, 120 chicks were used from each genotype. Four groups were formed: feed-restricted (FR) and infested with parasite $\left(\mathrm{P}^{+}\right)$, FR only, fed ad libitum and $\mathrm{P}^{+}$, and fed ad libitum only. Feed restriction was applied as $20 \%$ of the feed consumption of the group fed ad libitum the day before for each genotype. The study was conducted between 2 to 12 weeks of age. Weekly live weights and feed consumption were recorded, and the feed conversion ratio was calculated. Traps were placed in cages to count parasites. Regarding the live weight, NHR tolerated the PRM infestation in the ad libitum feed conditions better than other genotypes. While the infested NHR and AS birds had lower live weights than the non-infested ones under FR conditions, there was no difference between infested and non-infested birds of NHR and AS genotypes when they fed ad libitum. The feed consumption of infested AS and NHR birds was higher than that of non-infested counterparts when fed ad libitum. By contrast, the LS chicks consumed less food in the infested environment. In conclusion, the genotypes responded differently to PRM infestation in different feeding environments.
\end{abstract}

\section{Introduction}

Different genotypes in any environmental conditions can react differently to changing environmental conditions (Truberg and Huhn, 2000; Settar et al., 1999). This is called genotype and environment interaction (Bowman, 1972). Genotype-environment interaction (GE) can be seen as a change in the sequence of genotypes from one environment to another and as the difference in performance observed between environments or as a combination of the two (Truberg and Huhn, 2000). In GE, the performance of genotypes for a particular trait may increase/decrease in the same way, or one may increase and the other decrease, which is both biologically and economically important (Drinkwater and Hetzel, 1991). If GE is not significant, genetic performance can be determine with phenotypic means in different environments. However, if GE is significant, this mean will be masked by sub-environments where genotypes differ significantly in relative performance (Fox, et al., 1997). In other words, if there is a GE, the best genotype in any environment may not be the best genotype for the same phenotype in another environment (Mulder and Bijma, 2005).

The existence of GE can reduce the efficiency of breeding programs (Hammami et al., 2009). For this reason, GE is significant for the efficiency and sustainability of breeding programs in order to have information regarding which genotype has the best and worst performance in which environment.

Studies of GE have generally been conducted in environments that differ in one factor or are cumulative environ- 
ments. How GE performs in interactions between environments is not well known. It is even more difficult to explain GE in nested environments. In such conditions, it is necessary to approach the problem by estimating the qualities of the environments that affect performance. In other words, the hierarchy of the environments must be determined.

In this study, two environments with intertwined factors (parasite and feeding level), whose qualities are sharply separated from each other, are the subject as part of GE. In terms of the parasite environment, an environment contaminated with poultry red mite (Dermanyssus gallinae) is considered (Kirkwood,1967; Chauve, 1998, Sleeckx et al., 2019; Erdem et al., 2020; Yazgan et al., 2020). When birds are infested with poultry red mite (PRM), the organism primarily tries to increase the blood cell count to compensate for the loss of blood (Kilpinen et al., 2005). In addition, birds must overcome itching and skin irritation, which is a direct effect of PRM (Kilpinen et al.,2005; Kaoud and El-Dahshan, 2010; Sparagano et al., 2014; Erdem et al., 2020). Discomfort due to parasite infestation reduces the welfare of birds and decreases immunity; thus, it may cause growth retardation in young birds (Konyalı et al., 2013; Erdem et al., 2020). Qualitative and quantitative feed restriction, especially in broiler breeding, is widely used to control the effects of rapid growth (Hocking et al., 2002; Sahraei, 2012). The feeding level was chosen as a second environmental factor in the study because live weight gain, feed conservation ratio, and body condition deteriorate because of protein, energy, or feed intake restriction in animals (Yu et al., 1990; Roberts et al., 2007). On the other hand, if feed consumption is restricted in animals, it minimizes the basal metabolism, and growth and development slow down (Pym and Dillon, 1973; Yambayamba et al., 1996; Hornick et al., 2000).

Although Konyalı (2016) reported that the growth and development of different laying chicken genotypes were similarly affected by PRM infestation, it is not known how the interactions of different environments affect genotypes. There are indications that dietary factors may affect disease resistance (Blazer, 1992) and influence the severity of parasite infestations (Gyorgy, 1938; Ely and Harvey, 1969). On the other hand, it is not known whether restricted feeding in infestation conditions with PRM affects genotypes differently. In the light of these facts, the hypothesis of this study is that growth and development will be similarly affected by feed restriction of genotypes infested with PRM. In addition, it was accepted that the feeding level hierarchically represented the "upper environment" compared to the PRM infestation. This study therefore investigated how growth was affected in different laying chicken genotypes which were in the early growing stage and which were infested with PRM under feed restriction, and it examined whether genotypes responded equally to feed restrictions ins infested and noninfested environments.

\section{Materials and methods}

This study was conducted within the scope of the $\mathrm{PhD}$ thesis entitled "Quantitative Genetic Studies on Growth: Genotype Environment Interaction, Inbreeding and the Uniformity Problem" (unpublished). The research protocol was approved by the Ethics Committee of Çanakkale Onsekiz Mart University (approval date and number: 23 February 2018 2018/02-03).

In total, 120 female chicks were used from each genotype: Atak-S (AS), New Hampshire Red (NHR), and Light Sussex (LS). AS is a layer hybrid based on breeds of Rhode Island Red and Barred Rock developed at the Ankara Poultry Research Institute. The NHR genotype was developed in the US through intensive selection for the egg yield from Rhode Island Red. LS is a breed derived from local genotypes in the county of Sussex, United Kingdom.

The chicks were placed in cages at the age of 2 weeks with four chicks per cage. Two environmental factors known to affect each other, namely feeding level (F) and PRM infestation $(\mathrm{P})$, were considered. In this sense, four groups were created from each genotype (feed-restricted and infested $\left(\mathrm{FR} / \mathrm{P}^{+}\right)$, only feed-restricted $\left(\mathrm{FR} / \mathrm{P}^{-}\right)$, fed ad libitum and infested $\left(\mathrm{AL} / \mathrm{P}^{+}\right)$, and only fed ad libitum $\left.\left(\mathrm{AL} / \mathrm{P}^{-}\right)\right)$. The feedrestricted groups consisted of eight cages, and the groups fed ad libitum consisted of seven cages for each genotype. Feed restriction was applied as $20 \%$ of the $1 \mathrm{~d}$ feed consumption for the $\mathrm{AL} / \mathrm{P}^{-}$group of each genotype.

Birds were fed with a diet containing $21 \%$ crude protein up to 8 weeks of age and $15 \% \mathrm{CP}$ feed was used for the next 4 weeks. During the study, a 16L : 8D photoperiod was applied. Weekly live weight (LW) and feed consumption were observed with a $0.05 \mathrm{~g}$ precision scale. In the ad libitum groups, daily feed intake (DFI) per animal was recorded. The feed conversion ratio (FCR) per animal in both ad libitum and feed-restricted groups was calculated (FCR: (feed, g) - (live weight gain, $g)^{-1}$ ).

D. gallinae were collected from backyard henhouses from in and around Çanakkale city. Almost equal amounts of mites were placed in each trap/cage. The parasite population dynamic was observed in the traps. The traps were photographed at $6,8,10$, and 12 weeks of age of the birds. The average number of adult mites per $1 \mathrm{~cm}^{2}$ in a trap was counted; the mite population size was estimated. The area covered by the mite population was determined in the photographs, and the mite load was estimated. The study was terminated at the age of 12 week.

\section{Statistical analysis}

Analyses were completed separately for each FR and AL group. The variance analysis method was used in the model that includes genotype, parasite, and their interaction in the analyses of the initial and end-of-study live weights (Eq. 1).

$Y_{i j k}=\mu+g_{i}+p_{j}+g p_{i j}+e_{i j k}$, 
where $Y_{i j k}$ is the initial live weight or the end-of-study live weight, $\mu$ is the population mean, $g_{i}$ is the fixed effect of the $i$ th genotype, $p_{j}$ is the fixed effect of the $j$ th parasite group, $g p_{i j}$ is the interaction of genotype and parasite, and $e_{i j k}$ is the random residual.

The repeated measure variance analysis method was used in the model that includes genotype, parasite, age (week), and their interaction in the analysis of live weight by weeks (Eq. 2). In this model, the initial body weight (IBW) was included as a covariate. In the statistical analysis of DFI and FCR, the same model and method were used, except for the initial live weight (covariate). As a result of these analyses, interactions that were not significant were removed from the model.

$$
\begin{aligned}
Y_{i j k l m o} & =\mu+c_{i j k l m}+g_{j}+p_{k}+w_{l}+\beta x_{i j k l m} \\
& +(g X p)_{j k}+(g X w)_{j l}+(p X w)_{k l} \\
& +(g X p X w)_{j k l}+e_{i j k l m o},
\end{aligned}
$$

where $Y_{i j k l m o}$ is the weekly live weight, $\mu$ is the population mean, $c_{i j k l m}$ is the random effect of the $m$ th chick within $j$ th genotype, $k$ th parasite group, and age of $l$ th week, $g_{j}$ is the fixed effect of the $j$ th genotype, $p_{k}$ is the fixed effect of the $k$ th parasite group, $w_{l}$ is the fixed effect of the $w$ th week, $\beta$ is the regression coefficient, $x_{i j k l m}$ is the initial live weight of the $m$ th chick of the $i$ th genotype and the $j$ th parasite group, and $e_{i j k l m o}$ is the random residual.

The regression coefficients were used to compare the slopes of the weekly live weights of all subgroups. Orthogonal contrasts derived from the general linear model with an age-parasite-feeding-genotype interaction effect on weekly live weights were used to compare regression coefficients associated with each subgroup.

All the analyses were carried out with the SAS package program (2002).

\section{Results}

In Table 1, the least square means of live weight at the beginning and end of the study are shown for genotype, F, and $\mathrm{P}$ effects. As expected, there are significant differences between genotypes in terms of live weight at the beginning and end of the study ( $P=0.0122$ and $P<0.0001)$. No significant effect was found for the parasite-genotype interaction (PG) $(P=0.2399)$.

However, $\mathrm{P}$ affected the live weight of the birds in the restricted-feeding conditions at the end of the study ( $P=$ 0.0058). There is also a difference between genotypes in terms of live weight at the end of the trial $(P<0.0001)$.

The mite population was monitored from the age of 6 weeks of the chicks (Fig. 1). A decrease was observed after 8 weeks of age when the mite population was at the highest number with approximately 2 million.

The $P$ values of the variation sources related to weekly average live weight for parasite and genotype subgroups are

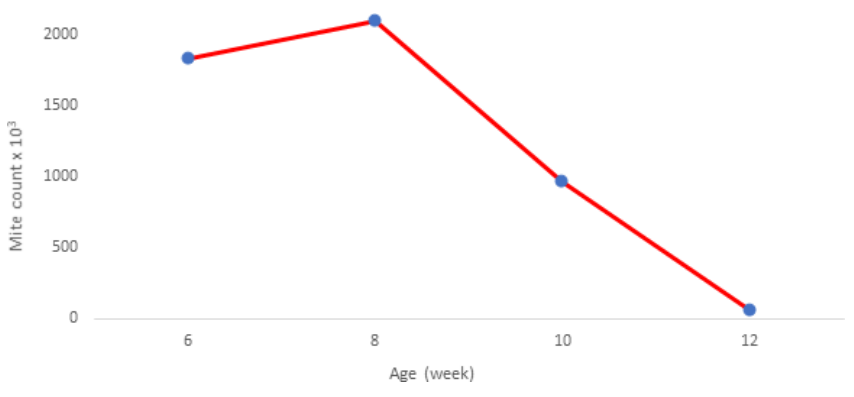

Figure 1. Mite population by weeks.

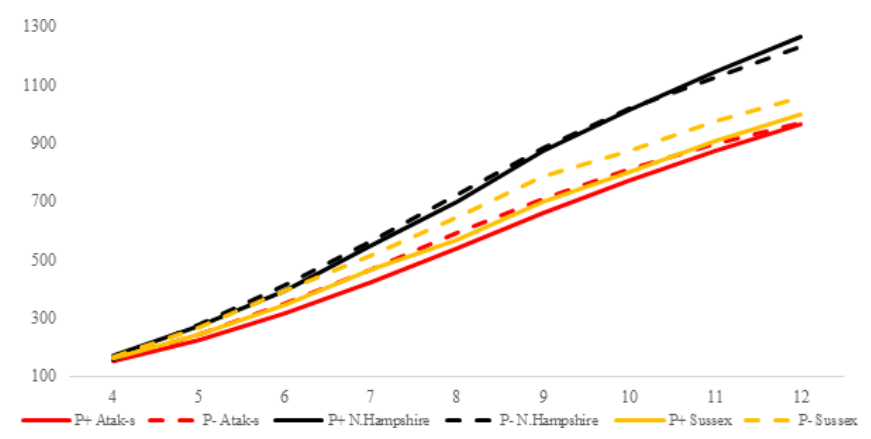

Figure 2. Trends of weekly average live weights for $\mathrm{P}^{+}$and $\mathrm{P}^{-}$ groups by genotype in an ad libitum environment (grams).

shown in Table 2 for each feeding environment. Their trends are seen in Figs. 2 and 3. In AL, the weekly live weights were significantly influenced by parasite, genotype, and PG effects $(P<0.0001)$. The NHR genotype had the highest live weight means during the study both in $\mathrm{P}^{+}$and $\mathrm{P}^{-}$. The NHR tolerated the PRM infestation in AL conditions and performed similarly based on weekly live weights in both $\mathrm{P}^{+}$and $\mathrm{P}^{-}$. At the end of the study, AL birds both with or without parasite infestation had similar live weights. However, the infested birds in the LS genotype during the study under AL feeding conditions had a lower LW average than the non-infested birds.

In the FR conditions, the difference is significant in weekly average live weight both in parasite environments and between genotypes $(P<0.0001)$. Especially after the age of 8 weeks, the difference in live weight between the noninfested and infested groups is remarkable. Under restrictedfeeding conditions, the AS birds were more affected by the infestation than the other genotypes. The PG was not significant $(P=0.1309)$.

In the feeding-level-parasite-genotype subgroups, the NHR is the fastest-growing genotype in both AL and FR environments in terms of the regression coefficients of weekly (age) live weights (Table 3). These birds also grow equally in $\mathrm{P}^{+}$and $\mathrm{P}^{-}$environments in both feeding environments. The growth rate of the AS birds in $\mathrm{P}^{+}$is relatively lower (4\%) than that of the $\mathrm{P}^{-}$birds. The LS genotype shows the same situation where the growth rate is $8 \%$ lower. $\mathrm{P}^{-}$birds show a 
Table 1. Least square means $(\bar{x})$ of live weights at the beginning and end of the study and their standard errors (SEs) and significance levels $(P)$ under ad libitum and restricted-feeding conditions in infested $\left(\mathrm{P}^{+}\right)$and non-infested $\left(\mathrm{P}^{-}\right)$birds.

\begin{tabular}{|c|c|c|c|c|c|c|c|c|}
\hline & \multicolumn{4}{|c|}{ Ad libitum } & \multicolumn{4}{|c|}{ Restricted } \\
\hline & \multicolumn{2}{|c|}{ Initial of study } & \multicolumn{2}{|c|}{ End of study } & \multicolumn{2}{|c|}{ Initial of study } & \multicolumn{2}{|c|}{ End of study } \\
\hline & $\bar{x}$ & SE & $\bar{x}$ & SE & $\bar{x}$ & SE & $\bar{x}$ & SE \\
\hline $\mathrm{AS}$ & 88.06 & 1.947 & 969.18 & 20.440 & 86.35 & 1.710 & 843.34 & 15.770 \\
\hline NHR & 93.87 & 1.965 & 1242.70 & 20.963 & 93.31 & 1.710 & 1006.40 & 16.085 \\
\hline LS & 85.79 & 1.947 & 1032.22 & 20.612 & 86.99 & 1.710 & 907.44 & 15.729 \\
\hline \multicolumn{9}{|c|}{$P$ value } \\
\hline $\begin{array}{l}\text { Parasite } \\
\text { Genotype } \\
\text { PG }\end{array}$ & $\begin{array}{l}0.9 \\
0.0 \\
0.9\end{array}$ & $\begin{array}{l}584 \\
22 \\
50\end{array}$ & \multicolumn{2}{|c|}{$\begin{array}{c}0.6962 \\
<0.0001\end{array}$} & $\begin{array}{l}0.9 \\
0.0 \\
0.5\end{array}$ & $\begin{array}{l}395 \\
72 \\
63\end{array}$ & $\begin{array}{r}0.00 \\
<0.0 \\
0.8\end{array}$ & $\begin{array}{l}58 \\
01 \\
32\end{array}$ \\
\hline
\end{tabular}

Table 2. Significance levels of variation sources for weekly live weights (LWs, g), feed conversion ratios (FCRs) separated by ad libitum and feed-restricted birds, and daily feed intake (DFI) per bird for birds fed ad libitum.

\begin{tabular}{lrr|rr|r}
\hline & \multicolumn{2}{c|}{ LW } & \multicolumn{2}{c|}{ FCR } & DFI \\
\cline { 2 - 6 } Source of variation & AL & FR & AL & FR & AL \\
\hline Initial live weight & $<0.0001$ & $<0.0001$ & - & - & - \\
Age & $<0.0001$ & $<0.0001$ & $<0.0001$ & $<0.0001$ & $<0.0001$ \\
Parasite & $<0.0001$ & $<0.0001$ & 0.6743 & 0.0481 & 0.0417 \\
Genotype & $<0.0001$ & $<0.0001$ & $<0.0001$ & 0.0015 & $<0.0001$ \\
Age-parasite & 0.2129 & $<0.0001$ & $<0.0001$ & $<0.0001$ & 0.0002 \\
Age-genotype & $<0.0001$ & $<0.0001$ & 0.0110 & 0.0500 & 0.1016 \\
Parasite-genotype & $<0.0001$ & 0.1309 & 0.2238 & 0.6802 & 0.0004 \\
Age-parasite-genotype & 0.9966 & 1.0000 & 0.7497 & 0.0005 & 0.8988 \\
\hline
\end{tabular}

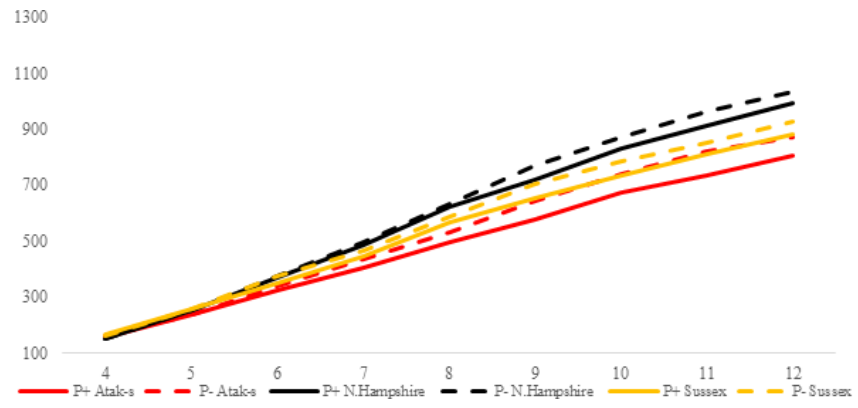

Figure 3. Trends of weekly average live weights for $\mathrm{P}^{+}$and $\mathrm{P}^{-}$ groups by genotype in feed-restricted environment (grams).

better growth performance than $\mathrm{P}^{+}$birds in AS and LS genotypes.

In the FR conditions, the NHR genotype is again the fastest-growing genotype. Also, the growth rate of the $\mathrm{P}^{+}$ and $\mathrm{P}^{-}$birds is close in these birds. In the AS genotype, the $\mathrm{P}^{+}$birds have an $8 \%$ lower slope than the $\mathrm{P}^{-}$birds. In the LS genotype, the $\mathrm{P}^{+}$birds have a $7 \%$ lower slope than the $\mathrm{P}^{-}$ birds. As in the AL conditions, the $\mathrm{P}^{-}$birds of the AS and LS genotypes also have a better growth performance than the

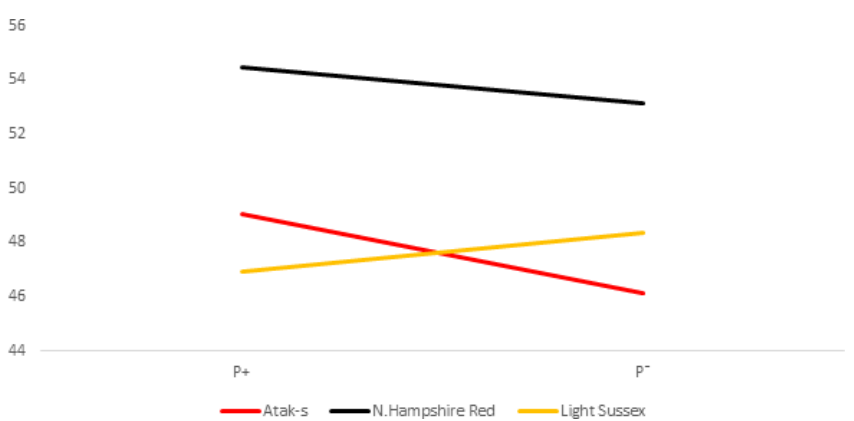

Figure 4. Daily feed intake (grams) per bird (DFI) for infested $\left(\mathrm{P}^{+}\right)$ and non-infested $\left(\mathrm{P}^{-}\right)$groups in ad libitum conditions ( $\left.\mathrm{AL}\right)$.

$\mathrm{P}^{+}$birds in the FR conditions. In the LS genotype, the proportional difference in growth rate between the $\mathrm{AL} / \mathrm{P}^{+}$and $\mathrm{FR} / \mathrm{P}^{-}$environments is close. On this basis, it can be said that, for the LS genotype, the infestation has almost the same effects in both feeding environments. In the AS genotype, however, the infected birds show a growth rate that is twice as low in the FR environment as it is in the AL environment.

The $P$ values of the sources of variation regarding the tendency of the DFI averages of the genotype and para- 
Table 3. Regression coefficients $(b, \mathrm{~g})$ and their standard errors (SEs) showing the slopes of the weekly live weights according to feeding level and parasite effects.

\begin{tabular}{|c|c|c|c|c|}
\hline Feeding & Parasite & Genotype & $b$ & SE \\
\hline \multirow{6}{*}{ Ad libitum } & \multirow[t]{3}{*}{ Infested $\left(\mathrm{P}^{+}\right)$} & Atak-S & $12.28^{\mathrm{a}}$ & 0.097 \\
\hline & & New Hampshire Red & $16.35^{\mathrm{b}}$ & 0.224 \\
\hline & & Light Sussex & $12.71^{\mathrm{c}}$ & 0.125 \\
\hline & \multirow[t]{3}{*}{ Non-infested $\left(\mathrm{P}^{-}\right)$} & Atak-S & $12.81^{\mathrm{c}}$ & 0.098 \\
\hline & & New Hampshire Red & $16.18^{\mathrm{b}}$ & 0.245 \\
\hline & & Light Sussex & $13.88^{\mathrm{d}}$ & 0.109 \\
\hline & \multirow[t]{3}{*}{ Infested $\left(\mathrm{P}^{+}\right)$} & Atak-S & $10.61^{\mathrm{e}}$ & 0.073 \\
\hline \multirow{5}{*}{ Restricted } & & New Hampshire Red & $13.72^{\mathrm{d}}$ & 0.196 \\
\hline & & Light Sussex & $11.68^{\mathrm{f}}$ & 0.072 \\
\hline & \multirow[t]{3}{*}{ Non-infested $\left(\mathrm{P}^{-}\right)$} & Atak-S & $11.57^{\mathrm{f}}$ & 0.075 \\
\hline & & New Hampshire Red & $14.05^{\mathrm{d}}$ & 0.175 \\
\hline & & Light Sussex & $12.54^{\mathrm{ac}}$ & 0.102 \\
\hline
\end{tabular}

All the regression coefficients are significantly different from $0(P<0.0001)$. Different letters indicate significant differences between the regression coefficients $(P<0.05)$.

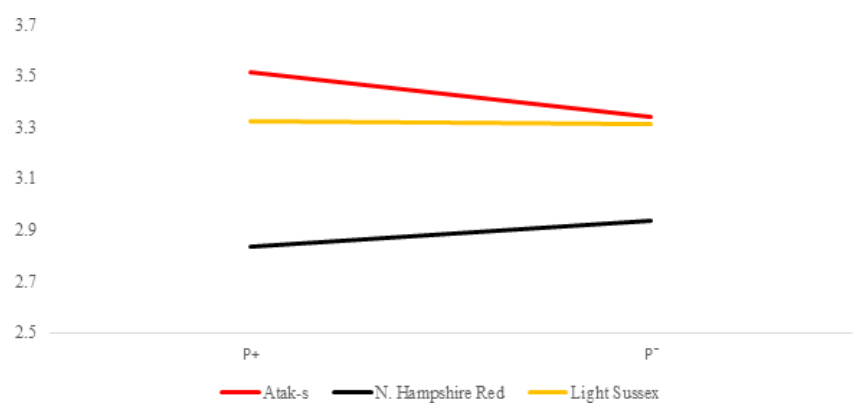

Figure 5. Averages of feed conversion ratio for infested $\left(\mathrm{P}^{+}\right)$ and non-infested $\left(\mathrm{P}^{-}\right)$groups in ad libitum conditions (AL); feed g / LW g.

site subgroups on the basis of weekly ages in the AL environment are shown in Table 2, whereas their averages are shown in Fig. 4. Parasite environment, genotype, and their interactions are significant for DFI (respectively, $P=0.0417$, $P<0.0001, P=0.0004)$. The AS and NHR birds grown in the infested environment consumed more feed than those grown in the non-infested environment. By contrast, the LS genotype consumed less feed in the infested environment than in the non-infested. According to the feed restriction method of the study, the feed intake of the FR groups was determined by the $\mathrm{AL} / \mathrm{P}^{-}$groups. Therefore, the $\mathrm{FR} / \mathrm{P}^{+}$ and $\mathrm{FR} / \mathrm{P}^{-}$birds consumed $20 \%$ less feed than the $\mathrm{AL} / \mathrm{P}^{-}$ groups.

Table 2 shows the $P$ values of the sources of the variation in the FCR at weekly age in the genotype and parasite subgroups in the AL and FR environment. Its averages are shown in Figs. 5 and 6. There is a difference between the genotypes in terms of FCR in the AL environment $(P<0.0001)$. While NHR is the best genotype in terms of FCR, AS and LS

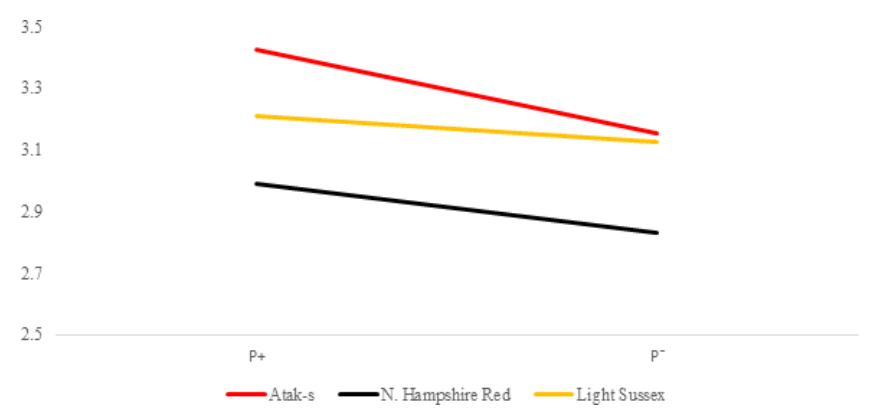

Figure 6. Averages of feed conversion ratio for infested $\left(\mathrm{P}^{+}\right)$and non-infested $\left(\mathrm{P}^{-}\right)$groups in feed-restricted conditions (FR); feed g / LW g.

are similar. Genotype-parasite interaction is not significant $(P=0.2238)$. The best FCR is found for the NHR genotype in the $\mathrm{P}^{+}$group, while the average FCR has nearly the same value in the AS and LS genotypes in the $\mathrm{P}^{-}$groups. The FCR value of the birds of the AS genotype decreased from 3.52 to 3.34, while that of the birds of the NHR increased from 2.83 to 2.93 in the $\mathrm{P}^{+}$and $\mathrm{P}^{-}$groups, respectively. In the LS genotype, this value almost did not change $\left(\mathrm{P}^{+}=3.32\right.$, $\mathrm{P}^{-}=3.31$ ).

In the FR environment, genotype and parasite effects influenced FCR significantly $(P=0.0015, P=0.0481$, respectively). However, the genotype-parasite interaction was not significant $(P=0.6802)$. The mean FCR of the $\mathrm{P}^{-}$groups had almost the same values in the AS and LS genotypes in the FR environment as in the AL environment. In the AS and LS genotypes, the mean FCR values decreased from the $\mathrm{P}^{+}$ environment to the $\mathrm{P}^{-}$environment (from 3.42 to 3.15 and from 3.21 to 3.12, respectively). Different from the AL environment, the mean FCR values of the NHR genotype in 
the FR environment decreased from the $\mathrm{P}^{+}$environment to the $\mathrm{P}^{-}$environment, in the same direction as for the other genotypes (from 2.99 to 2.83). Considering that the effect of the parasite is important in the AL environment and is not important in the FR environment, this situation points to an interaction in terms of environments related to FCR in the NHR genotype.

\section{Discussion}

While the study shows a significant PG interaction associated with LW in the birds fed ad libitum, it is not significant for the feed-restricted birds. The genotypes were affected differently by infestation in the AL environment but were similarly affected by infestation in the FR environment. The PG interaction related to FCR was not seen in both feeding environments. The PG interaction occurred in the birds in terms of DFI, which, of course, led to variation only in the AL environment.

Feed restriction is frequently used in poultry breeding, especially in broiler breeding, in order to prevent metabolic disorders and to keep live weight under control (Zubair and Leeson, 1994; Balog et al., 2000; Urdaneta-Rincon and Leeson, 2002; Camacho et al., 2004; Fassbinder-Orth and Karasov, 2006). However, the lack of nutrients (protein, energy, amount, etc.) during the growth phase leads to negative effects on growth such as decrease in live weight gain and deterioration in FCR (Vaughters et al., 1987; Plavnik and Hurwitz, 1990; Acar et al., 1995). The organism may have difficulties in dividing the insufficient supply of nutrients between internal complex functions (such as growth, development, repair, defense, and reproduction) (Coop and Kyriazakis, 1999). This situation may cause a malfunction in some body functions. On the other hand, some authors report that feed restriction does not affect immune-related parameters and that it, on the contrary, increases innate immunity (Hangalapura et al., 2005; Fassbinder-Orth and Karasov, 2006; Klasing, 2007; Khajavi et al., 2010).

In the AL environment, the $\mathrm{LW}$ difference between the $\mathrm{P}^{+}$ and $\mathrm{P}^{-}$birds' decrease or is not observed at all when the NHR and AS genotypes are considered (Fig. 2). The higher feed consumption of the $\mathrm{P}^{+}$birds compared to the $\mathrm{P}^{-}$birds (Fig. 4) may lead to overcoming the negative effects of the infestation. However, the opposite is the case with the LS genotype. The birds infected with PRM have a lower feed intake and a lower live weight than the non-infested LS. In fact, there are contradictory reports regarding the fact that the mite infestation causes birds to reduce or increase their feed consumption (Williams, 2003; Mul et al., 2009; Erdem et al., 2020). While the NHR and LS genotypes used in the study are pure breeds, the AS genotype is a hybrid one. However, this does not explain why NHR and AS have a higher feed intake, whereas LS has a lower feed intake. Hybrid genotypes are expected to be more resistant to bad environmen- tal conditions than pure genotypes due to the heterosis effect (Ali et al., 2000). Indeed, when the infested and non-infested chicks are compared, the results in the ad libitum environment show relatively better growth for the infested AS birds versus the LS birds. However, this result is not supported in feed-restricted birds.

Since the LW means of the genotypes are almost parallel to one another, Fig. 3 confirms that there is no interaction between genotype and environment in the FR conditions $(P=0.1309)$. In the FR environment, it can be clearly seen that the $\mathrm{P}^{+}$birds have a lower LW than the $\mathrm{P}^{-}$birds, even though the groups received the same amount of food.

When the growth of the AS and NHR genotypes is considered, it appears that a negative effect (the PRM infestation) is mitigated by a positive effect (ad libitum feeding). However, growth will be adversely affected if the appropriate conditions are not maintained (restricted feeding). Accordingly, the growth of the birds in the FR environment was significantly slowed compared to the AL birds and the NHR birds with the highest live weights were most affected. The AS and LS chicks were similarly affected by the feed restriction.

According to Shelford's law of tolerance (1931), an organism can survive in a range of lower and upper limits of a factor (tolerance range); in other words, it can tolerate this factor in this range. The tolerance range may vary depending on factors, as well as on organisms in terms of the same factor. Our results suggest that the live weight differences for each genotype between the infected birds and non-infested birds are smaller in the AL environment than in the FR environment. According to these results, the feeding environment is a limiting factor in the impact of the infestation.

The DFI means of the genotypes in Fig. 4 show a clear GE, resulting in a change in the genotype ordering (crossover). While the LS chicks consumed less food in the infested group than in the non-infested group, the AS and NHR birds consumed more in the infested group than in the non-infested group. However, while the differences of FCR between the $\mathrm{P}$ groups in both feeding environments are not significant, the apparent GE in Figs. 5 and 6 is also not significant. On the other hand, when looking at Figs. 5 and 6, there are slight differences in the slope of the genotypes due to the significant effects of the PRM in the FR environment compared to the insignificance in the AL environment. It is reported that parasitic diseases have adverse effects on FCR (Phengvichith and Ledin, 2007; Tellez et al., 2014; Yin et al., 2014). It is known that Dermanyssus gallinae increases feed intake and decreases growth, whereas it causes a deterioration in FCR (Kirkwood, 1967; Williams, 2003; Sleeckx et al., 2019; Erdem et al., 2020). In contrast, Erdem et al. (2020) reported that PRM-infested quails consume less food than non-infested quails. The direct or indirect effects of the parasites can lead to the underutilization of the nutrients used for growth and development, which worsens homeostasis. To maintain homeostasis, the host can increase feed intake, which could close the energy and protein deficit. However, if 
the host is unable to cope with the stress caused by the parasite, feed consumption may be reduced. Considering DFI and FCR, the genotypes appear to have different responses to infestation even when exposed to the same feeding environment.

In the FR environment, the NHR genotype appears to have difficulties in evaluating the feed offered in the $\mathrm{P}^{+}$group for growth and development as opposed to the $\mathrm{P}^{-}$group. It probably uses up some of its energy fighting the parasite. The NHR and AS chicks in the AL environment were not affected by this adverse situation by probably increasing feed intake. However, the effects of infestation are likely to be different for the LS genotype than for the other genotypes. Different mechanisms may underlie the reduction in feed intake under the PRM infestation. One of these may be the increase in scratching frequency caused by mite bites, which reduces the time the animal takes for feed intake (Konyalı et al., 2018; Erdem et al., 2020). Another reason can be called anorexia since the parasite causes physiological discomfort. It has been reported that brain serotonin activity, known to affect appetite physiology, is affected by external parasite infestations (Øverli et al., 2014).

\section{Conclusions}

A clear result of this study is that the change in the feeding environment caused changes in the reactions of the genotypes to the PRM infestation. Therefore, our hypothesis regarding the fact that the growth of the genotypes behaves similarly at different feeding levels in combination with the challenge of PRM infestation or non-infestation was rejected. However, our assumption that the feeding environment is hierarchically above the parasite infestation was proven.

Our results showed that a bird's genotype and feeding environment affect responses of young layer chickens to parasite challenge, and the results also indicated significant GE for growth performance.

Data availability. The data are available from the corresponding author upon request.

Author contributions. This study was conceptualized by TS. TS and HE designed the experiment. HE collected the data. TS and HE analyzed the data and wrote the paper.

Competing interests. The contact author has declared that neither they nor their co-author has any competing interests.
Disclaimer. Publisher's note: Copernicus Publications remains neutral with regard to jurisdictional claims in published maps and institutional affiliations.

Acknowledgements. This work was supported by the Scientific Research Coordination Unit of Çanakkale Onsekiz Mart University under project number FBA-2018-2502. This article is dedicated to Prof. Dr. İ. Yaman Yurtman.

Review statement. This paper was edited by Manfred Mielenz and reviewed by two anonymous referees.

\section{References}

Acar, N., Sizemore, F. G., Leach, G. R., Wideman, R. F., Owen, R. L., and Barbato, G. F.: Growth of broiler chickens in response to feed restriction regimens to reduce ascites, Poult. Sci., 74, 833843, https://doi.org/10.3382/ps.0740833, 1995.

Ali, K. O., Katule, A. M., and Syrstad O.: Genotype $\times$ environment interaction in growing chickens: comparison of four genetic groups on two rearing systems under tropical conditions, Acta. Agric. Scand. A, 50, 65-71, https://doi.org/10.1080/09064700412331312301, 2000.

Blazer, V. S.: Nutrition and disease resistance in fish, Ann. Rev. Fish Diseases, 2, 309-323, https://doi.org/10.1016/09598030(92)90068-9, 1992.

Balog, J. M., Anthony, N. B., Cooper, M. A., Kidd, B. D., Huff, G. R., Huff, W. E., and Rath, N. C.: Ascites syndrome and related pathologies in feed restricted broilers raised in a hypobaric chamber, Poult. Sci., 79, 318-323, https://doi.org/10.1093/ps/79.3.318, 2000.

Bowman, J. C.: Genotype $\times$ environment interactions, Ann. Genet. Sel. Anim., 4, 117-123, 1972.

Camacho, M. A., Suárez, M. E., Herrera, J. G., Cuca, J. M., and García-Bojalil, C. M.: Effect of age of feed restriction and microelement supplementation to control ascites on production and carcass characteristics of broilers, Poult. Sci., 83, 526-532, https://doi.org/10.1093/ps/83.4.526, 2004.

Chauve, C.: The poultry red mite Dermanyssus gallinae (De Geer, 1778): Current situation and future prospects for control, Vet. Parasitol., 79, 239-245, https://doi.org/10.1016/s03044017(98)00167-8, 1998.

Coop, R. L. and Kyriazakis, I.: Nutrition-parasite interaction, Vet. Parasitol., 84, 187-204, https://doi.org/10.1016/s03044017(99)00070-9, 1999.

Drinkwater, R. D. and Hetzel, D. J. S.: Applications of molecular biology to understanding genotype-environment interactions in livestock production, in: Isotope and Related Technıques in Animal Production and Health, Vienna, Austria, 15-19 April 1991, 437-452, 1991.

Ely, D. G. and Harvey, T. L.: Relation of ration to shortnosed cattle louse infestations, J. Econ. Entomol., 62, 341-344, https://doi.org/10.1093/jee/62.2.341, 1969.

Erdem, H., Konyalı, C., Akbağ, H. I., and Savaş, T.: Growth, behavioural and haematological responses to poultry red mite 
infestation in Japanese quail, Europ. Poult. Sci., 84, 305, https://doi.org/10.1399/eps.2020.305, 2020.

Fassbinder-Orth, C. A. and Karasov, W. H.: Effects of feed restriction and realimentation on digestive and immune function in the leghorn chick, Poult. Sci., 85, 1449-1456, https://doi.org/10.1093/ps/85.8.1449, 2006.

Fox, P. N., Crossa, J., and Romagosa, I.: Multi-environment testing and genotype $\times$ environment interaction, Statistical Methods for Plant Variety Evaluation, edited by: Kempton, R. A. and Fox, P. N., Chapman \& Hall, London, England, 117-138, https://doi.org/10.1007/978-94-009-1503-9_8, 1997.

Gyorgy, P.: Pediculosis in rats kept on a riboflavindeficient diet, Exp. Biol. Med., 38, 383-385, https://doi.org/10.3181/00379727-38-9863, 1938.

Hammami, H., Rekik, B., and Gengler, N.: Genotype by environment interaction in dairy cattle, Biotechnol. Agron. Soc. Environ., 13, 155-164, https://doi.org/10.1007/BF00265180, 2009.

Hangalapura, B. N., Nieuwland, M. G., De Vries Reilingh, G., Buyse, J., Van Den Brand, H., Kemp, B., and Parmentier, H. K.: Severe feed restriction enhances innate immunity but suppresses cellular immunity in chicken lines divergently selected for antibody responses, Poult. Sci., 84, 1520-1529, https://doi.org/10.1093/ps/84.10.1520, 2005.

Hocking, P. M., Bernard, R., and Robertson, G. W.: Effects of low dietary protein and different allocations of food during rearing and restricted feeding after peak rate of lay on egg production, fertility and hatchability in female broiler breeders, Br. Poult. Sci., 43, 94-103, https://doi.org/10.1080/00071660120109908, 2002.

Hornick, J. L., Van Eenaeme, C., Gérard, O., Dufrasne, I., and Istasse, L.: Mechanisms of reduced and compensatory growth, Domes. Anim. Endocrin., 19, 121-132, https://doi.org/10.1016/S0739-7240(00)00072-2, 2000.

Kaoud, H. A. and El-Dahshan, A. R.: Effect of red mite (Dermanyssus gallinae) infestation on the performance and immune profile in vaccinated broiler breeder flocks, J. Amer. Sci., 6, 72-79, 2010.

Khajavi, M., Rahimi, S., Hassan, Z. M., Kamali, M. A., and Mousavi, T.: Effect of feed restriction early in life on humoral and cellular immunity of two commercial broiler strains under heat stress conditions, Br. Poult. Sci., 44, 490-497, https://doi.org/10.1080/000071660310001598328, 2010.

Kilpinen, O., Roepstorff, A., Permin, A., Nørgaard-Nielsen, G., Lawson, L. G., and Simonsen, H. B: Influence of Dermanyssus gallinae and Ascaridia galli infections on behaviour and health of laying hens (Gallus gallus domesticus), Br. Poult. Sci., 46, 26-34, https://doi.org/10.1080/00071660400023839, 2005.

Kirkwood, A. C.: Anaemia in poultry infected with red mite Dermanyssus gallinae, Vet. Rec., 80, 514-516, https://doi.org/10.1136/vr.80.17.514, 1967.

Klasing, K. C.: Nutrition and the immune system, Br. Poult. Sci., 48, 525-537, https://doi.org/10.1080/00071660701671336, 2007.

Konyalı, C., Erdem, H., Coşkun, B., and Savaş, T.: The effect of poultry red mite infestation (Dermanyssus gallinae) on feed intake and body weight change at early growth period of chicks, II. Organic animal husbandry congress, Bursa, Turkey, 24-26, 2013.

Konyalı, C.: Effects of the poultry red mite (Dermanyssus gallinae (Acari : Dermanyssidae)) on growth performance in growing chickens from different genotypes, Phd Thesis. Çanakkale Onsekiz Mart University, Çanakkale, Turkey, 189 pp., 2016.

Konyalı, C., Erdem H., and Savaş, T.: Can animal behaviors be used as an indicator for the control of poultry red mite? 10th Animal Science Congress, Antalya, Turkey, 2018.

Mul, M., Van Niekerk, T., Chirico, J., Maurer, V., Kilpinen, O., Sparagano, O., Thind, B., Zoons, J., Moore, D., Bell, B., Gjevre, A. G., and Chauve, C.: Control methods for Dermanyssus gallinae in systems for laying hens: results of an international seminar. World Poult. Sci. J., 65, 589-599, https://doi.org/10.1017/S0043933909000403, 2009.

Mulder, H. A. and Bijma, P.: Effects of genotype $\times$ environment interaction on genetic gain in breeding programs, J. An. Sci., 83, 49-61, 2005.

Øverli, Ø., Nordgreen, J., Mejdell, C. M., Janczak, A. M., Kittilsen, S., Johansen, I. B., and Horsberg, T. E.: Ectoparasitic sea lice (Lepeophtheirus salmonis) affect behavior and brain serotonergic activity in Atlantic salmon (Salmo salar L.): perspectives on animal welfare, Physiol. Behav., 132, 44-50, https://doi.org/10.1016/j.physbeh.2014.04.031, 2014.

Phengvichith, V. and Ledin, I.: Effect of a diet high in energy and protein on growth, carcase characteristics and parasite resistance in goats, Trop. Anim. Health Prod., 39, 59-70, https://doi.org/10.1007/s11250-006-4443-z, 2007.

Plavnik, I. and Hurwitz, S.: Performance of broiler chickens and turkey poults subjected to feed restriction or to feeding of lowprotein or low-sodium diets at an early age, Poult. Sci., 69, 945952, https://doi.org/10.3382/ps.0690945, 1990.

Pym, R. A. E. and Dillon, J. F.: Restricted food intake and reproductive performance of broiler breeder pullets, Br. Poult. Sci., 15, 245-259, https://doi.org/10.1080/00071667408416104, 1974.

Roberts, A. J., Paisley, S. I., Geary, T. W., Grings, E. E., Waterman, R. C., and MacNeil, M. D.: Effects of restricted feeding of beef heifers during the postweaning period on growth, efficiency, and ultrasound carcass characteristics, J. Anim. Sci., 85, 2740-2745, https://doi.org/10.2527/jas.2007-0141, 2007.

SAS Institute Inc: SAS/STAT ${ }^{\circledR} 9.3$ User's Guide. Cary, NC, 2011.

Sahraei, M.: Feed restriction in broiler chickens production, Biotechnol. Anim. Husb., 28, 333-352, https://doi.org/10.2298/BAH1202333S, 2012.

Settar, P., Yalcin, S., Turkmut, L., Ozkan, S., and Cahanar, A.: Season by genotype interaction related to broiler growth rate and heat tolerance, Poult. Sci., 78, 1353-1358, https://doi.org/10.1093/ps/78.10.1353 1999.

Shelford, V. E.: Some consepts of bioecology, Ecology, 12, 455467, https://doi.org/10.2307/1928991, 1931.

Sleeckx, N., Van Gorp, S., Koopman, R., Kempen, I., Van Hoye, K., De Baere, K., Zoons, J., and De Herdt, P.: Production losses in laying hens during infestation with the poultry red mite Dermanyssus gallinae, Avian Pathol., 48, 17-21, https://doi.org/10.1080/03079457.2019.1641179, 2019.

Sparagano, O. A. E., George, D. R., Harrington, D. W. J., and Giangaspero, A.: Significance and control of the poultry red mite, Dermanyssus gallinae, Annu. Rev. Entomol., 59, 447-66, https://doi.org/10.1146/annurev-ento-011613-162101, 2014.

Tellez, G., Shivaramaiah, S., Barta, J., Hernandez-Velasco, X., and Hargis, B.: Coccidiosis: Recent advancements in the immunobiology of eimeria species, preventive measures, and the importance of vaccination as a control tool against these apicomplexan 
parasites, Veterinary Medicine: Research and Reports, 23, 2334, https://doi.org/10.2147/VMRR.S57839, 2014.

Truberg, B. and Huhn, M.: Contributions to the analysis of genotype $\mathrm{x}$ environment interactions: comparison of different parametric and non-parametric tests for interactions with emphasis on crossover interactions, J. Agron. Crop. Sci., 185, 267-274, https://doi.org/10.1046/j.1439-037x.2000.00437.x, 2000.

Urdaneta-Rincon, M. and Leeson, S.: Quantitative and qualitative feed restriction on growth characteristics of male broiler chickens, Poult. Sci., 81, 679-688, https://doi.org/10.1093/ps/81.5.679, 2002.

Vaughters, P. D., Pesti, G. M., and Howarth, B.: Effects of feed composition and feeding schedule on growth and development of broiler breeder males, Poult. Sci., 66, 134-146, https://doi.org/10.3382/ps.0660134, 1987.

Williams, R. E.: Livestock and poultry: Control of poultry pests. Department of Entomology, Purdue University Cooperative Extension Service, Indiana, USA, Fact Sheet No. E-3, 2003.

Yambayamba, E. S. K, Price, M. A., and Jones, S. D. M.: Compensatory growth of carcass tissues and visceral organs in beef heifers, Livest. Prod. Sci., 46, 19-32, https://doi.org/10.1016/0301-6226(96)00014-0, 1996.
Yazgan, N., Eralp E., Konyalı, C., Kamanlı, S., and Savaş, T.: Effects of poultry red mite (Dermanyssus gallinae) and storage on egg quality in white layers, J. Anim. Prod., 61, 33-40, https://doi.org/10.29185/hayuretim.669679, 2020.

Yin, F., Dan, X., Sun, P., Shi, Z., Ga,o Q., Peng, S., and Li, A.: Growth, feed intake and immune responses of orange-spotted grouper (Epinephelus coioides) exposed to low infectious doses of ectoparasite (Cryptocaryon irritans), Fish. Shellfish. Immun., 36, 291-298, https://doi.org/10.1016/j.fsi.2013.11.019, 2014.

Yu, M. W., Robinson, F. E., Clandinin, M. T., and Bodnar, L.: Growth and Body Composition of Broiler Chickens in Response to Different Regimens of Feed Restriction, Poult. Sci., 69, 2074 2081, https://doi.org/10.3382/ps.0692074, 1990.

Zubair, A. K. and Leeson, S.: Effect of early feed restriction and realimentation on heat production and changes in sizes of digestive organs of male broilers, Poult. Sci., 73, 529-538, https://doi.org/10.3382/ps.0730529, 1994. 